\title{
Misclassification of Nutrition Status among Elderly Based on Combination of Stature Predictor by Martha Irene Kartasurya
}

Submission date: 13-Dec-2019 04:08PM (UTC+0700)

Submission ID: 1233782092

File name: 1.pdf (1.84M)

Word count: 2690

Character count: 14486 


\title{
Misclassification of Nutrition Status among Elderly Based on Combination of Stature Predictor
}

\author{
Julia Pertiwi ${ }^{1}$, Martha Irene Kartasurya ${ }^{2}$, Djoko Tri Hadi Lukmono ${ }^{1}$, Henry Setyawan ${ }^{3}$, Martini $^{3}$ \\ ${ }^{\prime}$ Master Program of Epidemiology, School of Postgraduate Studies Diponegoro University, Semarang, \\ Indonesia, 50241; ' Department of Biology, Faculty of Sciences and Mathematics, Diponegoro, University, \\ Semarang, Indonesia, 50275; ${ }^{3}$ Department Epidemiology and Tropical Diseases, Faculty of Public Health, \\ Diponegoro University, Semarang, Indonesia, 50275
}

\begin{abstract}
The combination of arm span and knee height as the stature predictors on elderly was arranged to obtained the most precise and accurate prediction of actual height. However, there was not much research that calculated prediction errors. This study aimed to measure the size of the misclassification of elderly nutritional status which calculated by predictive combination regression model. The study was an observational study with cross-sectional design. The study population was 60-69 years old men and women in Wonogiri District, Central Java. The sample size were 65 men and 71 women, which were chosen purposively in the community. Anthropometric measurements on knee height and arm span and the actual height were done by standardize technique. Data of BMI were analysed us $1 \mathrm{~g}$ Friedman pos hoc Wilcoxon test then clasified to nutrition status to calculated sensitivity and specificity. Among the men subjects, the overweight and underweight status using BMI were overestimate by $8.3 \%$ and $12.5 \%$, respectively. Among the women subjects, overestimate also occurred on underweight by $12.5 \%$. In all respondents, underestimation of underweight was $7.2 \%$ and overestimation in the normal nutritional status was $3.7 \%$. It was concluded that some misclassification of BMI, by predicted height among elderly based with combination regression model was found.
\end{abstract}

Keywords: misclassification; height; combination of predictors; nutrition status

\section{INTRODUCTION}

Body Mass Index (BMI) was a simple calculation to monitor nutritional status in individuals (aged $>18$ years) by comparing body weight (in kilograms) and squares of height (in meters) then categorized them. ${ }^{1}$ Therefore, height was an important variable to assessed nutritional status at the elderly. However, the height measurement generally performed in stand position could not applied to elderly people who have lost the ability to stand. Thus, World Health Organization recommended arm span and knee height as a predictor of elderly height. ${ }^{1}$

\footnotetext{
Corresponding Author:

Julia Pertiwi

Master Program of Epidemiology,

School of Postgraduate Studies Diponegoro University, Jalan Imam Barjo S.H. Nomor 5, Semarang Selatan,

Pleburan, Kota Semarang,

Jawa Tengah, Indonesia, 50241

Email: pertiwijulia26@gmail.com
}

Using arm span and knee height as a predictor of height in elderly would directly affected the results of calculation of BMI and determined the nutritional status. When overestimation occured at the height it would increase the prevalence of underweight while whereas an estimate below the actual height (underestimation) would increase the prevalence of overweight. The condition would affected to made large prevalence of malnutrition in the elderly, further impact will also lead to inaccuracy in health policy making related that problems. ${ }^{2}$

Phenomenon of overestimation and underestimation of high prediction results would affected the categorization of nutritional status and affected the prevalence of nutrition in the elderly. Research in Sweden showed the lowest prevalence of underweight with knee height BMI compared to actual BMI and Chumlea. ${ }^{3}$ Prevalence of obesity was higher (overestimation) based on measurement of knee height BMI than actual BMI. Obesity diagnosis in men based on knee height BMI was $26.2 \%$ while based on actual BMI was $17.5 \%$. It could be 
interpreted that the prevalence of obesity based on knee height BMI was twice higher than actual BMI. ${ }^{3}$ Other studies have shown that overestimation of height was calculated based on knee height on female respondents reached $2.22 \mathrm{~cm}$ and caused underestimation of BMI reached $10 \%{ }^{4}$

A study developed a formula using two predictors. Theoretically it was done because the more variables $\mathrm{x}$ added the more degrees of freedom lost. So, the study arranged regression model of the elderly by combining arm span and knee height. ${ }^{5}$ The predictor formula were:

$$
\begin{aligned}
& \text { Women }=40.915+(0.457 \times \mathrm{AS})+(0.818 \times \mathrm{KH}) \\
& \text { Men }=34.426+(0.513 \times \mathrm{AS})+[0.813 \times \mathrm{KH})
\end{aligned}
$$

With:

(1) : Formula for predicted women's elderly height

(2) : Formula for predicted men's elderly height.

AS : The measurement result of arm span in centimeters.

$\mathbf{K H}$ : The measurement result of knee height in centimeters.

The study showed highest overestimation happened at Chumlea's formula in men was $6.01 \mathrm{~cm}$ and highest underestimation happen at Fatmah's formula in women group was $-0.72 \mathrm{~cm} .^{5}$ While, combination predictor showed the lowest underestimation in men and women with the smallest average difference compared with the long and high knee predictors. ${ }^{5}$

The combination of predictors has more accurate ability to predicted height in the elderly. However, no further calculation has been done on body mass index and diagnosed malnutrition in the elderly.

\section{METHOD}

Research Design: The type of research was observational analytic with cross sectional study. Cross sectional study was suitable for correlation research with the observation approach (point time approach). ${ }^{6}$

Study Subject and Sample Size: Actual BMI as dependent variable, combination predictor's BMI as independent variables. The results of this study presented in men and women's groups.

Study population at this study was individuals aged 60-69 years in Wonogiri sub district at January July 2017. Inclusion criteria were individuals in health conditions, able to stand upright and willing to be respondent by filling informed consent. The exclusion criteria were when the individuals have unable stretched his or her arms properly (straight) because of a broken or physical disability and experiencing foot fractures and or using prosthetic limbs. The sample selection method was purposive sampling included 65 men and 71 women.

Measurements: Measurements on each respondent were repeated three times and then taken the mean value of the measurement results by standardized enumerator and standardized measurement (shows in Fig 1). The measurement results were recorded by the researchers on the provided sheet.

Arm span was measured with arm line that was modified. There was a tape measuring ("BUTTERFLY" brand) with a precision of $1 \mathrm{~mm}$ attached to the luminum rod (shows in Fig 2). Arm span was measured from the tip of the middle finger of one hand to the tip of the middle finger of the other hand with the individual standing with their back to the wall with both arms abducted to $90^{\circ}$, the elbows and wrists extended and the palms facing directly forward. Body mass index estimated from the arm span was calculated through combination predictors and Fatmah formulas. ${ }^{7}$

Knee height was measured with knee height caliper belonging to Nutrition Laboratory of Public Health Faculty, Diponegoro University with $1 \mathrm{~mm}$ of accuracy (shows in Figure 2). Measurements were performed on the left knee with the perfect sitting position (upright body, hands free down and facing directly forward). Make sure each knee forms $90^{\circ}$ angle, consisting of a fixed part, which has been positioned in the plantar surface of the foot (heel) and movable part, which was positioned over the patella. Body mass index estimated from the arm span was calculated through combination predictors and Chumlea's formulas. ${ }^{8}$

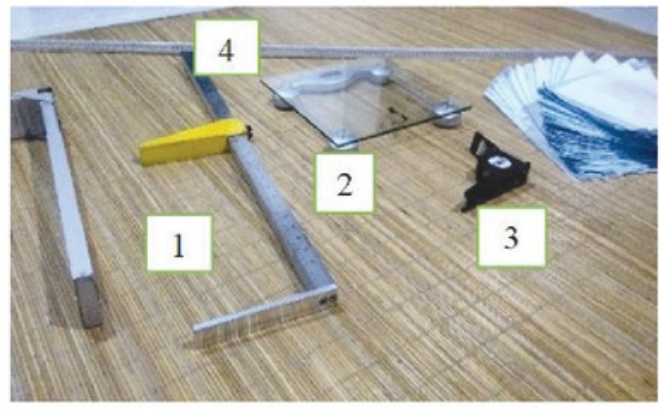

Figure 1: (1) Knee height caliper; (2) Digital scale for weight measurement; (3) Actual height measurement; (4) Arm span measurement 


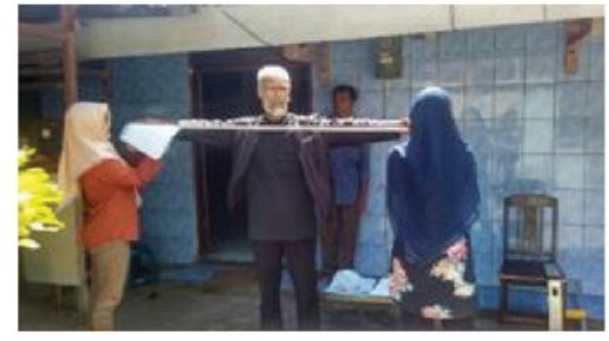

(1)

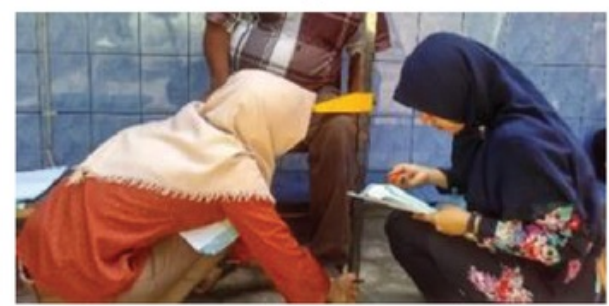

(2)

Figure 2. (1) A respondent was measured the arm span by enumerator; (2) A respondent was measured the knee height by enumerator

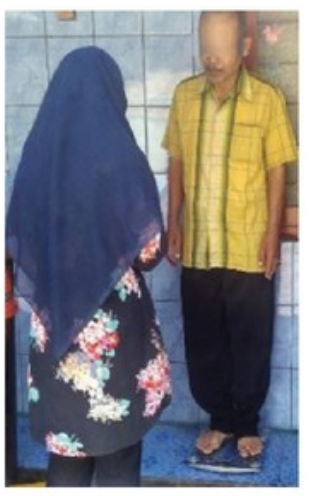

(1)

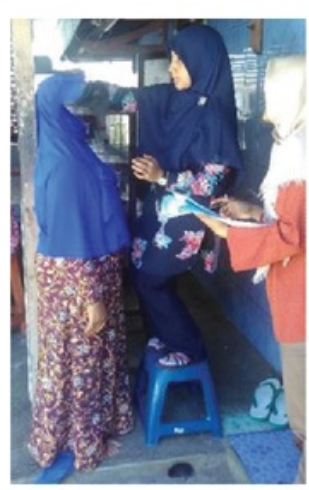

(2)
Figure 3: (1) A respondent was measured the actual height by enumerator; (2) A was measured the weight by enumerator

Actual height was measured by microtoise "GEA" SH-2A series with $1 \mathrm{~mm}$ of accuracy (shows in Figure 3). Standing height was measured with microtoise against the wall on barefooted subjects, with their heels together and the heels, buttocks touching the wall.

Digital scales brand "CAMRY" series EB9-4A with $0.1 \mathrm{~kg}$ accuracy to measure weight (shows in Figure 3). Enumerator asked respondents to remove shoes or footwear, jackets, hats, and others. Then, they allowed them to step up onto the digital scale, right in the middle of the stamping place. The enumertor adjusted respondent's position to stand upright with his eyes facing forward and not moving. They also ensured that the respondent was not touching or being touched or touched by another. Process of measuring the respondent shown in Figure 1, Figure 2 and Figure 3.

\section{RESULTS AND DISCUSSIONS}

Mean Difference Test Of Body Mass Index: Table 1 shows that there's difference BMI between combination predictor's formula, Chumlea's formula and Fatmah's formula in men and women. There's only BMI's combination predictor formula that similar with BMI's actual predictor in men $(\mathrm{p}=0.883)$ and women $(\mathrm{p}=0.184)$.

Table 1: Result of Mean Difference Test

\begin{tabular}{|c|c|c|}
\hline \multirow{2}{*}{ BMI (kg/m $\left.\mathbf{m}^{\mathbf{2}}\right)$} & \multicolumn{2}{|c|}{ Sex } \\
\cline { 2 - 3 } & Men* $^{*}$ & Women $^{* *}$ \\
\hline Actual & $21.46 \pm 3.28$ & $21.93 \pm 3.45$ \\
\hline Combination Predictor & $21.40 \pm 3.26$ & $21.94 \pm 3.44$ \\
\hline Chumlea & $21.32 \pm 3.27$ & $20.22 \pm 3.18$ \\
\hline Fatmah & $20.97 \pm 3.20$ & $22.15 \pm 3.47$ \\
\hline p value & $<0,001^{\mathrm{a}}$ & $<0,001^{\mathrm{b}}$ \\
\hline
\end{tabular}

Note:

* Normality test for Actual BMI $\mathrm{p}=0.192$, Combination Predictor's BMI $\mathrm{p}=0.088$, Fatmah's BMI $\mathrm{p}=0.027$, and Chumlea's BMI $\mathrm{p}=0,200$

** Normality test for Actual BMI $\mathrm{p}=0.040$, Combination Predictor's BMI $\mathrm{p}=0.047$, Fatmah's BMI $\mathrm{p}=0.031$, and Chumlea's BMI $\mathrm{p}=0,082$

${ }^{a}$ Friedman test result. Post hoc Wilcoxon test Actual vs Combination Predictor 0.883; Actual vs Chumlea 0.031 ; Actual vs Fatmah $<0.001$; Combination Predictor vs Chumlea 0,006; Combination Predictor vs Fatmah $<0.001$; Chumlea vs Fatmah $<0.001$.

${ }^{\mathrm{b}}$ Friedman test result. Post hoc Wilcoxon test Actual vs Combination Predictor 0.184; Actual vs Chumlea $<0.001$; Actual vs Fatmah $<0.001$; Combination Predictor vs Chumlea 0,006; Combination Predictor vs Fatmah $<0.001$; Chumlea vs Fatmah $<0.001$.

The highest difference in BMI was found in the female was calculated by Chumlea's formula $(1.70 \mathrm{~kg} /$ $\left.\mathrm{m}^{2}\right)$ and Fatmah's formula in men $\left(0.43 \mathrm{~kg} / \mathrm{m}^{2}\right)$. Predictor combinations show the lowest difference.

BMI is a reliable indicator for body fatness for most people. BMI does not measure body fat directly, 
but studies have shown that BMI correlates with body fat, such as water weight and dual energy x-ray absorptiometry [8]. BMI can be considered as an alternative to direct measures of body fat. In addition, BMI methods are easy and inexpensive.

Increasing age there are physiological and pathological changes in a person. This situation makes the elderly become very susceptible to a disease. Diseases in the elderly usually occur in many organs so that drug administration must polypharmacy. Polypharmacy means the use of multiple drugs at once in a patient, more than is required logically-rationally associated with an estimated diagnosis. Among the many medications that was swallowed by elderly there was some drug interactions can lead to hospitalization or death. The main diseases that attack the elderly are hypertension, heart failure and infarction and heart rhythm disorders, diabetes mellitus, impaired kidney function and liver. In addition, there are also situations that often interfere with the elderly such as impaired cognitive function, balance the body, sight and hearing. All these circumstances cause elderly to receive treatment of many kinds. ${ }^{9}$ Problems that arise when the elderly sick are the doses of drugs that would be given should right. Growing age will affected to LADME system. It means changes in drug release from dosage form, absorption, distribution, metabolism and drug excretion. In this case, the elderly group needs special attention. Drug dose calculations can be based on age, weight, body surface area and Body Mass Index (BMI). Calculation of dose with body surface area claimed most accurately. ${ }^{10}$

Diagnostic Test On Combination Predictors to Determine Nutritional Status: Comparison of nutritional status was calculated based on predictors and actual height in women and men group showed in Fig 4 and Fig 5.

Women's BMI which was calculated by a combination of predictors resulted 2 error in the diagnosis of nutritional malnutrition and showed an overestimation phenomenon. Although with the same diagnosis error, nutritional malnutrition that calculated with BMI of combination predictor in men showed underestimation phenomenon. In Chumlea showed high underestimation reached 11 people in women and overestimated 6 people in men. Difference in underestimation of 4 women and 4 overestimations in men if the BMI is calculated by the Fatmah formula. (Shown in Figure 4 and Figure 5).

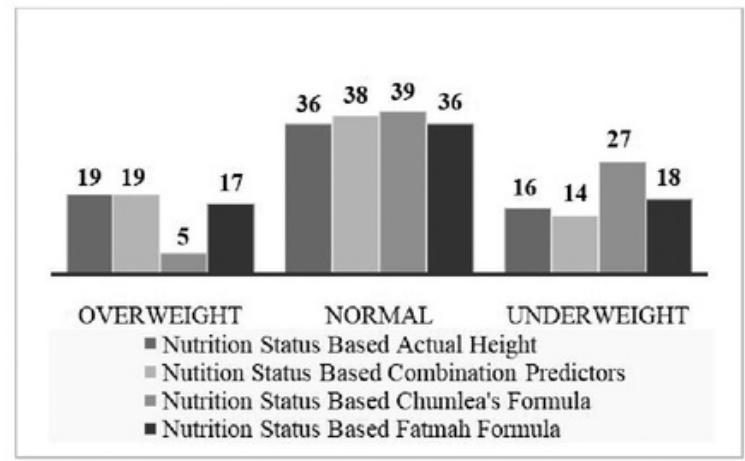

Figure 4: Comparison of Nutritional Status based Various Formula and Actual Height in Women Respondents

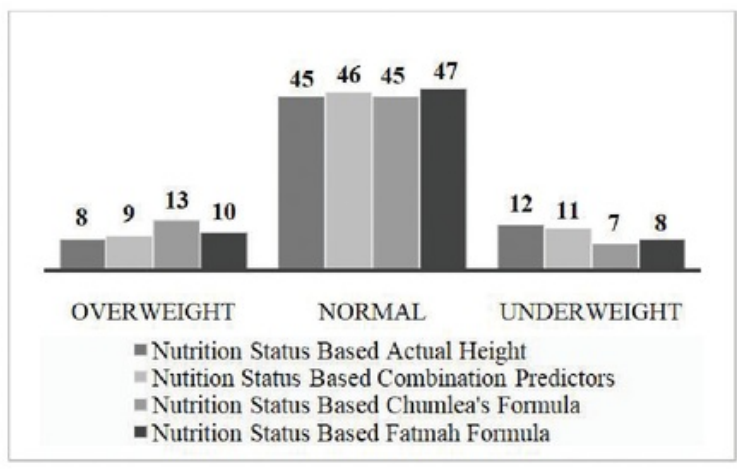

Figure 5: Comparison of Nutritional Status based Various Formula and Actual Height in Men Respondents

Then, there were calculate of the sensitivity and specificity of combination predictors when used to determine nutritional status. The results of the analysis were shown on the Tab 2. The results of calculations showed sensitivity was $90.90 \%$ and specificity was $95.60 \%$. When the value was $>80 \%$, it mean that the regression model has a good diagnostic test for malnutrition in the elderly. Previous research in Indonesia on new diagnostic tests was performed on a body mass index measured by arm span and knee height. The results show that the length of the depa has a sensitivity value of $78 \%$ and knee height has a sensitivity of $69 \%$. This value is at a weak strength. ${ }^{?}$

Theoretically combination predictor can give more accurate the number of elderly because more variables $\chi$ added the more degrees of freedom lost. It is proved in this research with specificity value $95,06 \%$ and 
sensitivity $90,90 \%$. Thus the regression model with this predictor combination can be used to predict the height of the elderly in an effort to produce values with high accuracy. Thus, the risk of inaccuracy dosage of medication that would be given to sick elderly can be minimized.

Table 2: Diagnostic Test Table

\begin{tabular}{|c|c|c|c|}
\hline & & $\begin{array}{r}\text { Nutrition Status Based } \\
\text { Actual Height }\end{array}$ \\
\cline { 3 - 4 } & & Malnutrition & Normal \\
\hline $\begin{array}{c}\text { Nutrition } \\
\text { Status Based } \\
\text { Combination } \\
\text { Predictors }\end{array}$ & Malnutrition & 50 & 4 \\
\cline { 2 - 4 } & Normal & 5 & 77 \\
\hline
\end{tabular}

$$
\begin{aligned}
& \text { Sensitivity }=a /(a+c) \\
& \text { Specificity }=d /(b+d) \\
& =90.90 \%
\end{aligned}
$$

Specificity of Combination Predictor $=77 /(4+77)$

$$
=95.06 \%
$$

\section{ACKNOWLEDGEMENTS}

All lecturer from Master's Program in Epidemiology, Postgraduate School and Department of Public Health Nutrition, Faculty of Public Health, Diponegoro University, Indonesia who has conducted this research. The enumerator team who has provided support in collecting and analyzing the data in this study.

Ethical Clearance: Taken from Public Health Faculty, Diponegoro University Ethics Committee on July 14, 2017 with Number 165/EC/FKM/2017.

Source of Funding: Self.

\section{Conflict of Interest: Nil.}

\section{REFERENCES}

1. Chittawatarnat K, Sakda P, Vibul T. Height Perdiction from Anthropometric Length Parameters in Thai People. Asia Pacific Journal Clinical Nutrition. 2012; 2(3):347-354.

2. World Health Organization. Physical Status: The Use and Interpretation of Anthropometry. Geneva. 1999:365-368.

3. Gavriilidou, M. Pihlsgård, Elmståhl. High Degree Of BMI Misclassification of Malnutrition among Swedish Elderly Population: Age-Adjusted Height Estimation using Knee Height and Demispan. European Journal of Clinical Nutrition. 2016; 69(2):565-571.

4. Fogal AS, Sylvia C.C.F, Silvia E.P. Stature Estimation Using The Knee Height Measurement Amongst Brazilian Elderly. Nutrition Hospital. 2015; 31(2):829-834.

5. Julia P, Martha I.K, Djoko T.H.P. A Calculating Actual Stature of Elderly through Arm Span and Knee Height Measurements. Health Notions. 2018; 2(2).

6. Notoatmodjo, S. Metode Penelitian Kesehatan. Jakarta: Rineka Cipta. 2012; 76-78.

7. Fatmah. Predictive Equations for Estimation of Strature from Knee Height, Arm Span, and Sitting Height ini Indonesian Javanese Elderly People. International Journal of Medicine and Medical Science. 2006; 1(10):456-461.

8. Chumlea WC, Guo S. Equations for Predicting Stature in White and Black Elderly Individuals: Journal Gerontology. 1992; 47:197-203.

9. Darmansjah, I. Polifarmasi pada Usia Lanjut: Jurnal Ilmiah. 1994; 1(1):1-5.

10. Grummer-Strawn L.M. Centers of Assessing Your Weight: About BMI for Adult. (Online: http:// cdc.gov/healthyweight/assessing/bmi/adult_bmi/ index.html [Accesed on July 25. 2018] 


\section{Misclassification of Nutrition Status among Elderly Based on Combination of Stature Predictor}

ORIGINALITY REPORT

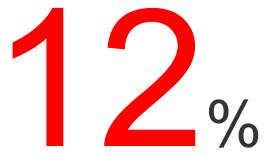

SIMILARITY INDEX
$5 \%$

INTERNET SOURCES
$5 \%$

PUBLICATIONS
$13 \%$

STUDENT PAPERS

PRIMARY SOURCES

1

Submitted to Universitas Diponegoro

Student Paper

2 medind.nic.in

Internet Source

Exclude quotes

Off

Exclude bibliography

Off
Exclude matches

$<2 \%$ 